\title{
A privatização da violência
}

Antonio Luiz Caldas Junior ${ }^{1}$

2 MARX, K., ENGELS, F. Textos. São Paulo: Edições Sociais, 1976.

${ }^{3}$ Tradução do Novo Mundo das Escrituras Sagradas. São Paulo: Sociedade Torre de Vigia de Bíblias e Tratados, 1986.
A partir do texto "Trote, Tradição e Violência" permito-me fazer breves reflexões sobre o tema em nossa sociedade.

1 Valores e comportamentos dos humanos decorrem de suas condições materiais de subsistência e não o contrário (Marx provou isso suficientemente) ${ }^{2}$. Justificar determinados comportamentos com base apenas na "tradição", carece, pois, de fundamento. As tradições só subsistem se sobrevivem seus determinantes estruturais. O milenar "mito da virgindade" sucumbiu em apenas uma geração. Nossas avós suportavam a idéia de casar virgens, aos catorze, quinze, dezoito anos, se muito. As mudanças da inserção da mulher no mercado de trabalho e a postergação do casamento, para além dos vinte, trinta anos, fez ruir o mito. Afinal, "o espírito, naturalmente está ansioso, mas a carne é fraca” (Marcos 14:38)3. O mundo subjetivo sucumbe ao objetivo. Igualmente, é a violência da vida cotidiana que sustenta a "cultura da violência" dos veículos de comunicação e não o contrário. Não há, pois, como defender a prática do trote com base apenas na subsistência de uma tradição.

2 A "tradição cultural" é pontuada freqüentemente de violência e tragédias pessoais e sociais, próprias da barbárie pré-histórica, indignas, nos dias atuais. Milhões de mulheres tiveram seus pés mutilados na China feudal $e$ capitalista. Outros milhões são submetidas anualmente, na África, à violência

\footnotetext{
${ }^{1}$ Médico, professor do Departamento de Saúde Pública da Faculdade de Medicina de Botucatu - Unesp.
} 
da clitoridectomia. E quem perpetra e perpetua estas "tradições"? As mesmas mulheres que há pouco dela foram vítimas. Sinais de "incivilidade"? Mas, não fazem o mesmo os civilizados membros da Real Marinha Australiana ao humilharem seus "calouros"? 3 Não causa qualquer surpresa, pois, que pessoas "da classe média", "sem problemas sociais ou econômicos", se envolvam em atos de violência e, em casos extremos, de morte. Nem cabe acreditar que a violência seja um "predicado" das classes populares. Ao contrário, a violência sempre existiu na classe dominante, já que é exatamente por ela que a dominação de classe é garantida. Que violência maior haveria do que aquela decorrente da fome, da miséria, das seqüelas impostas pela exploração predatória da escravidão, do colonialismo e do imperialismo, agora travestido de "globalização"? 4 O que alarma as classes médias e a burguesia é a percepção de que a violência (que sempre existiu) agora lhes chega à porta, inclusive pelas mãos de seus próprios filhos. Assim ocorre nos EUA, Inglaterra, ou Brasil: jovens "bem situados" incendeiam um índio em Brasília; aqui $e$ ali, filhos naturais $e$ adotivos executam seus pais, avós, irmãos, colegas de escola; o encontro de um corpo é o resultado indesejável do "ritual de passagem" da mais conceituada Faculdade de Medicina do país.

5 Ora, onde encontrar resposta para a disseminação incontida e tolerada da violência, que nos ameaça e com a qual, banalizada, de alguma forma, nos acostumamos? Certamente, muitas são as respostas. Entretanto, gostaria de destacar que nossa sociedade sucumbe ante uma ideologia que é a negação do sentimento coletivo, da cooperação, da colaboração e da solidariedade (que subsistiu, nem que fosse apenas no plano formal, até mesmo sob o capitalismo monopolista). Hoje, o (neo)liberalismo assume, sem dissimulação, os pressupostos da competição, da concorrência e da sobrevivência seletiva como condições necessárias à chamada "nova ordem econômica mundial". Fermenta a exclusão social e a violência. O navio naufraga, e o comandante anuncia que os escaleres, em número insuficiente, serão ocupados pelos mais "competitivos". Como garantir nesta circunstância qualquer norma de convivência e respeito razoavelmente civilizados e solidários?

6 Em crise, o capitalismo acirra suas contradições econômicas e sociais. Coexiste, porém, uma profunda crise das ideologias que dominaram o comportamento social no presente século ${ }^{4}$. No campo idealista, sucumbe o neo-positivismo em sua expressão funcionalista, calcada em conceitos tais como integração, totalidade, equilíbrio, ajuste e controle social. Naufraga o Estado-de-bem-estar-social, de inspiração keynesiana, que vendia a ilusão do progresso e desenvolvimento social para todos. De outra parte, o pensamento marxista ainda se ressente da derrocada das experiências socialistas do leste europeu. O materialismo histórico e dialético, solidário e comunista por essência, mergulha em reflexões sobre os descaminhos e erros cometidos em seu nome.

7 Neste cenário, atendendo às necessidades ideológicas da exclusão econômica (neo)liberal e aproveitando-se dos erros de um coletivismo que em muitos momentos nos negou a necessária e justa individualidade, difunde-se, especialmente dentre as classes médias, o pensamento

\footnotetext{
${ }^{4}$ NUNES, E. D. (org)

Juan César Garcia: Pensamento social em saúde na América Latina. São Paulo: Cortez, 1989.
} 
competitivo e personalista, que absolutiza o individualismo e o subjetivismo fenomenológico. O foco ideológico e político, sobre sociedade e classes sociais, amesquinha-se nos domínios do ervaçal idealista, do misticismo, das comunidades fechadas, dos pequenos grupos, das "tribos" e, no extremo, no mais absoluto privativismo, de conteúdo quase sempre reacionário.

8 Desde meus tempos de Escola Paulista de Medicina, sempre abominei o trote, fosse como calouro fosse como veterano. Como segundanista, até tentei experimentá-lo, sem sucesso. Achei tudo aquilo (humilhação, gritos, ovos, água etc.) desprovido de qualquer sentido humano. De quem consinta cortar os cabelos, pintar o corpo, é até aceitável. Violentar, humilhar, desrespeitar opinião e valores íntimos, jamais!

9 A despeito de tudo, o trote, no passado, era uma instituição coletiva $e$ como tal submetia-se a regras do senso comum. Havia verdadeiras batalhas com a presença, quase unânime de veteranos e (compulsoriamente) calouros. Enfim, uma violência consensualmente admitida e tolerada, como aliás tantas outras a que me referi. Pois, queiramos ou não, até a violência comporta (ou comportava) regras coletivas ou uma "ética da transgressão" (isto é, transgredir dentro de limites "socialmente toleráveis").

10 Porém, nos últimos anos, o trote privatiza-se. Muitos são os alunos que, sabiamente, abandonam as práticas degradantes e buscam fórmulas receptivas. A ruptura com o sentimento coletivo exalta, no entanto, pequenos grupos que transformaram o trote num tormento inqualificável $e$ em práticas que vão da violência física (como o "tradicional" "afogamento" em vasos sanitários) ao atentado violento ao pudor (como a nudez compulsória e a introdução de objetos no reto). Práticas que a despeito do esforço de uns poucos e da "indiferença" da maioria da comunidade universitária, vicejam aqui mesmo em nosso câmpus. Práticas $e$ comportamentos fomentados pela ideologia que, pretendendo-se pósmoderna, talvez explique e até justifique a triste morte do jovem Edson Tsung-Chi Hsueh na piscina da Associação Atlética Acadêmica da mais conceituada Faculdade de Medicina do país.

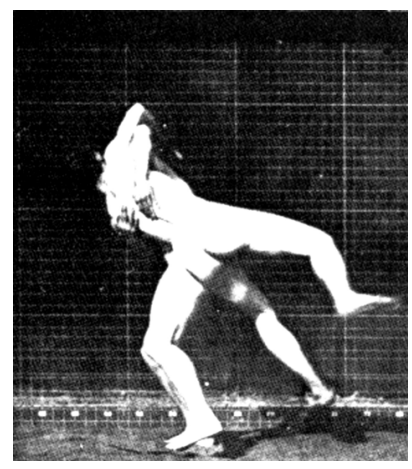



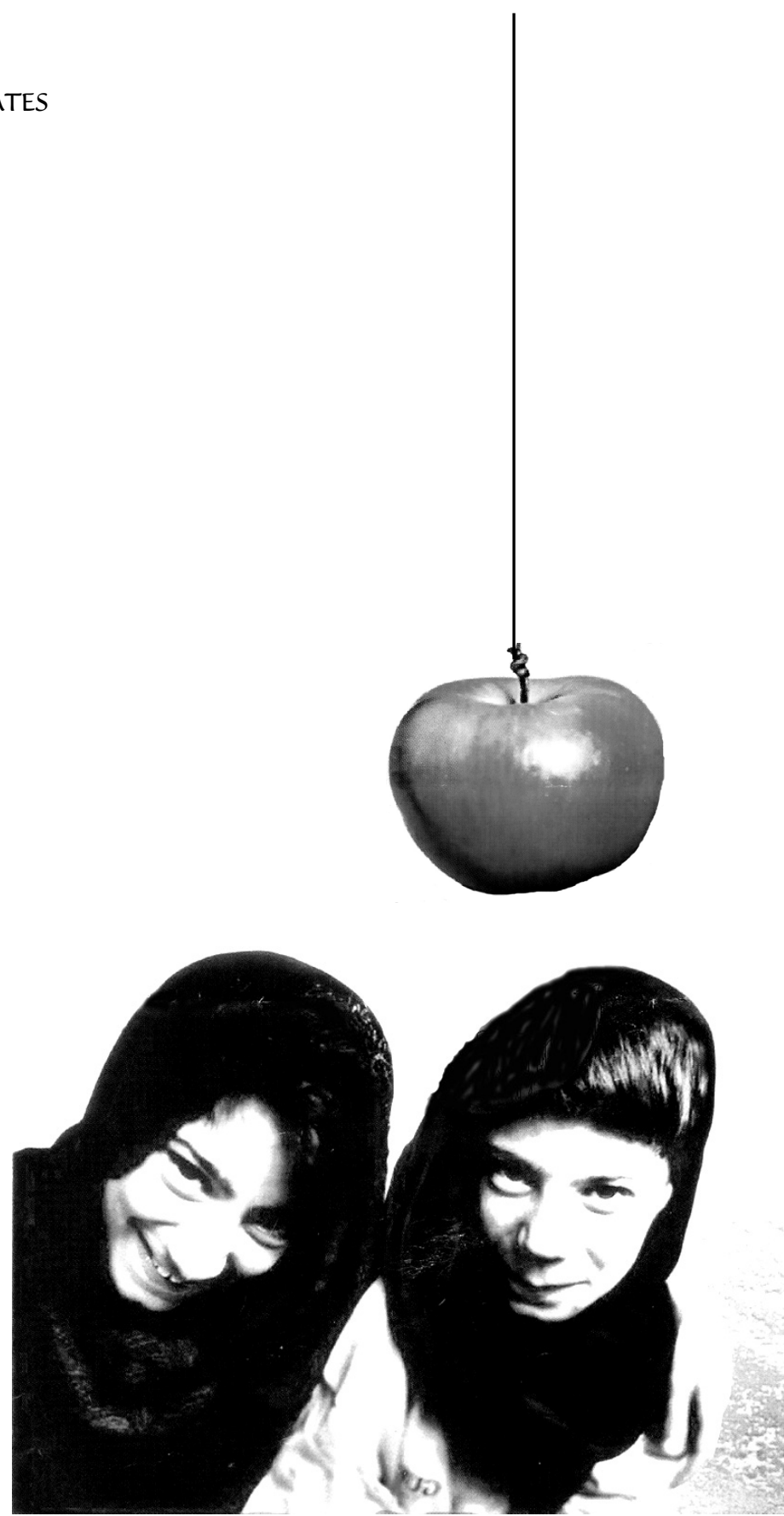

Num bairro periférico de Teerã, as irmãs Zahara e Massoumeh passaram treze anos aprisionadas em casa... pelo pais que as amam...

(Material de divulgação do filme A maçã, Samira Makhmalbaf, $22^{\circ}$ Mostra Internacional de Cinema, ã 1998).
O universo feminino reprimido...

a história da revolução islâmica... 